\title{
The effect of liquid diet on the parotid gland and the protective role of L-carnitine: immunohistochemical and ultrastructural study
}

\author{
T.A. ElGhamrawy \\ Department of Anatomy, Faculty of Medicine, Cairo University, Cairo, Egypt
}

[Received 2 May 2014; Accepted 22 June 2014]

Background: The moisture content of diet and the dryness of the mouth alter the volume of parotid saliva secreted in rats and it plays an important part in mastication and swallowing. Temporary or permanent liquid diet feeding provides a nutritional regime for patients in certain medical situations. The aim of the present work is to investigate the sequel of liquid diet on parotid gland in rats and the possible protective role of L-carnitine (L-car).

Materials and methods: Thirty adult male albino rats were divided into three groups (10 per group) - Control group: rats were fed on regular pellet diet, Liquid diet group and Liquid diet supplemented with L-car group were received liquid diet. The parotid glands were dissected for histological, immunohistochemical and ultrastructural analysis.

Results: By light microscope, liquid fed group showed some areas with degenerated irregularly shaped acini and atrophic acini with vacuolated cytoplasm and pyknotic nuclei. Acinar cells of parotid gland group on liquid diet supplemented with L-car, had normally eosinophilic cytoplasm with few vacuoles in their acinar cells. Periodic acid Schiff (PAS) staining, in liquid fed group showed that the serous acini were weakly stained with PAS that was localised in the apical portion of the cells where the secretory granules lie with lack of staining of the vacuoles. However, moderately stained acinar epithelial cell and fewer vacuoles was seen in group given liquid diet supplemented with L-car. Immunohistochemistry of Caspase 3 showed more apoptotic cells with increased area per cent of Caspase 3 immunoexpression, seen in the acini and more in the ductal epithelium in liquid fed group. It was markedly reduced in the acinar cells in group on liquid diet supplemented with L-car. Electron microscopic study revealed in liquid fed group acini with multiple cytoplasmic vacuoles and reduced secretory granules, degenerated swollen mitochondria and dilated cisternae of endoplasmic reticulum. Degenerated condensed nuclear mass or indented nuclear membrane, nuclei with karyorrhexis and chromatin material leaked in the cytoplasm with rupture of the nuclear membranes were also seen. In parotid gland of liquid fed group supplemented with L-car, acinar cells showed normally distributed secretory granules and few cytoplasmic vacuoles. They showed normal appearance of the nuclei and their cytoplasmic organelles.

Conclusions: Liquid diet caused cellular degenerative damages and apoptotic changes in parotid gland and these changes can be prevented by L-car supplementation probably by its antioxidant properties. (Folia Morphol 2015; 74, 1: 42-49)

Key words: parotid, liquid diet, L-carnitine, Caspase 3, ultrastructure 


\section{INTRODUCTION}

The parotid gland is the largest salivary gland in human, secreting serous fluid containing amylase protein. Parotid amylase plays a significant role in digesting polysaccharides. It is supposed to suppress adhesion to the vestibule surface and teeth [41]. Saliva is also rich in fluids and ions important for oral health. Temporary or permanent liquid diet feeding provides a broad regime of medical solutions in geriatric patients, gastrointestinal disorders, intensive care, tumour resection post-operative period, and reconstruction of facial structures and treatment fractures requiring fixation and appliances [12, 14, 24]. Some babies in the infancy period had delayed weaning and prolonged breast feeding. Also, a soft diet is advised in medical conditions like xerostomia [10].

The moisture content of diet and the dryness of the mouth alter the volume of parotid saliva secreted and parotid saliva plays an important part in mastication and swallowing [18]. Several experimental studies explored liquid diet consumption and found that it has been held responsible for causing degenerative changes and atrophic changes on submandibular glands [18, 34]. Diet-induced glandular alterations are known to occur as a result of chewing restriction. Functional stimulation is an important factor in the development, growth and stability of submandibular glands and liquid diet led to glandular atrophy [22], while higher levels of salivary secretion were detected in animals that were fed with solid diet [18]. Investigating the parotid gland changes on liquid diet is thought in need to shed light on.

The role of apoptosis in atrophy of parotid glands of rats fed liquid diets has received little study. Apoptosis is reportedly common in atrophy of exocrine glands. For example, epithelial cell numbers decrease by apoptosis during involution of the lactating mammary glands after weaning [29]. Acinar cells undergo apoptosis in the atrophic pancreas induced by duct obstruction [40], and similar observations were reported in atrophy of parotid glands following duct ligation $[11,27]$. Caspase 3 was used as an immunohistochemical marker for apoptosis, as it is cleaved at apoptotic cascade activation resulting in structural alterations of apoptotic cells [17].

The role of antioxidants in averting the atrophy of salivary glands received little attention. Only a single study investigated the protective effect of selenium on atrophy of submandibular gland of rats fed on liquid diet regimen [24]. L-carnitine (L-car), a quater- nary ammonium compound, serves as a key compound required for the transport of long-chain fatty acids into the mitochondria for energy production in tissues $[5,13,16]$. It is biosynthesized mainly in the liver, kidney and brain from the essential amino acids lysine and methionine [6]. Its antioxidant mechanism appears to be secondary to L-car reduction in mitochondrial reactive oxygen species production [23]. Numerous studies have investigated the beneficial effect of antioxidants in tissue [30, 39]. However, information regarding the effect of L-car in stressed salivary glands is scanty.

The purpose of the present study was first, to analyse the morphological changes that occurred in the parotid glands of rats maintained on short term liquid diet compared to solid diet and, second, the possible protective effect of L-car supplementation studied with using histological, immunohistochemical and ultrastructural techniques.

\section{MATERIALS AND METHODS}

\section{Experimental design}

The present study was carried out on 30 adult male albino rats, weighing 180-250 g. They were kept on a $12 \mathrm{~h}$ light-dark cycle and given food and water ad libitum. They were randomly divided into three groups (10 per group): (1) Control group (G1) ( $n=10)$ : rats were fed on regular pellet diet. (2) Liquid diet group (G2) $(n=10)$ : rats were fed a liquid diet, prepared by mixing two parts of water with one part of a powdered diet of the above pellet diet. (3) Liquid diet supplemented with L-car group (G3) ( $n=10)$ : rats L-car (100 mg/kg) was given via intraperitoneal route for 10 days [9]. L-carnitine hydrochloride (C0283) was purchased from Sigma-Aldrich, Germany. One month from the beginning of the experiment, all animals were euthanised by intraperitoneal injection of $120 \mathrm{mg} / \mathrm{kg}$ sodium pentobarbital. The parotid glands were dissected for histological, immunohistochemical and ultrastructural analysis.

\section{For light microscope}

The parotid gland was fixed in $10 \%$ formol saline solution, processed, embedded in paraffin, sectioned and stained with haematoxylin and eosin and periodic acid Schiff (PAS) stains to show the positivity for polysaccharide substances in the tissue [4].

\section{For immunohistochemical staining}

The sections that were collected on poly-L-lysine coated slides were subjected to heat pretreatment in 

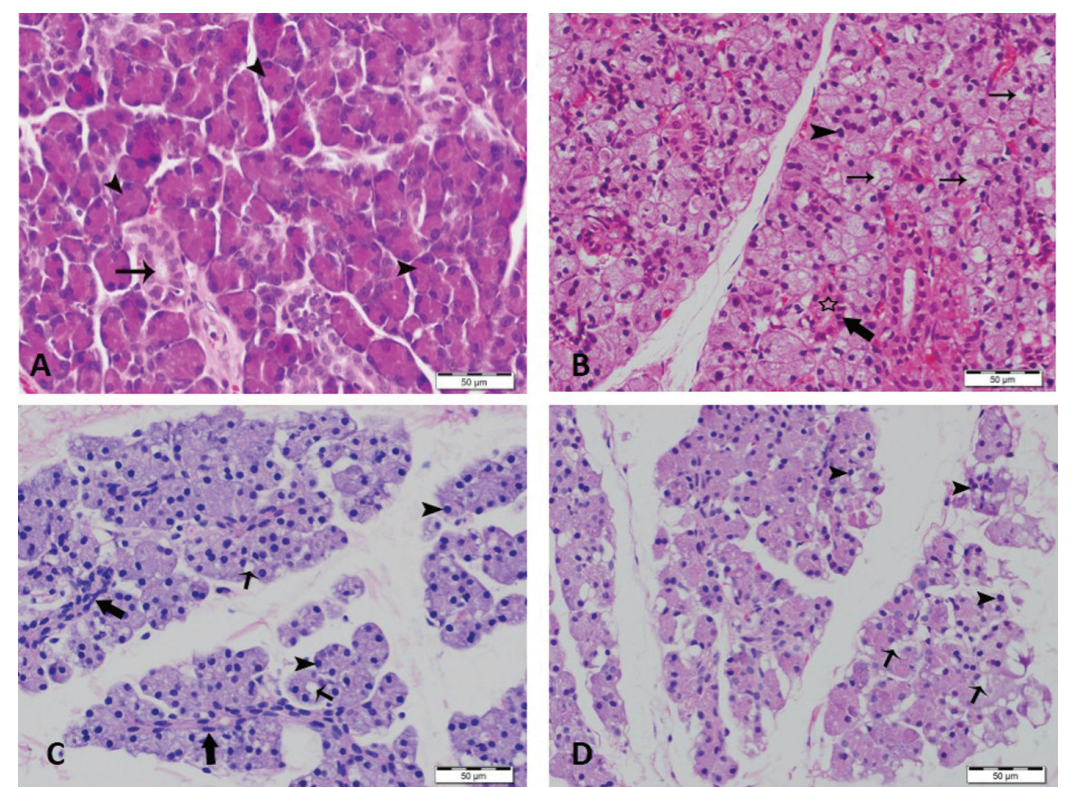

Figure 1. A. Light photomicrograph of a section in the parotid gland of control group showing serous acini with pyramidal cells (arrowhead) surrounding a small central lumen with spherical, basal nuclei. The connective tissue stroma shows striated ducts lined with cuboidal epithelium (short arrow); B, C, D. Sections in the parotid gland of liquid fed group showing: B. Areas with vacuolated acini (short arrow) uniformly distributed in whole parotid tissue and pyknotic nuclei (arrowhead) in the acinar cells. The striated ducts show pyknotic (thick arrow) and ghost shaped nuclei (asterisk); C, D. Markedly vacuolated, irregularly shaped acini (short arrow) and their cells show pyknotic nuclei (arrowhead). Note the intercalated and striated ducts that are cut longitudinally (thick arrow) surrounding the atrophic acini $(H \& E \times 400)$. citrate buffer. Then, they were incubated with the primary antibody for 30 min: Caspase 3 antibody, rabbit polyclonal antibody, catalogue number: PA5-16335, LabVision Corporation, Thermoscientific, USA. The marker was immunohistochemically localised using $A B C$ peroxidase method. Secondary polyclonal antibody formed of biotinylated anti-polyvalent antibody, streptavidin peroxidase and diaminobenzidine was applied. Localisation was visualised with diaminobenzidine and counter-stained in Meyer's haematoxylin, dehydrated, and mounted. Negative control sections were performed with the same procedure mentioned before except that the primary antibody was replaced by non-immune goat serum [3].

\section{Morphometric study and statistical analysis}

Histological and immunohistochemical sections were submitted for image analysis. The area per cent of Caspase 3 immunostaining was measured. Measurements were done in 10 non-overlapping fields for each animal at $\times 400$. This was done using the image analyser computer system "LeciaQwin 500 C" (Cambridge, UK). The data obtained were statistically analysed by comparing the mean values of different groups by one way analysis of variance ANOVA test using SPSS 9 software. P value $<0.05$ were considered statistically significant [31].

\section{Ultrastructural study}

Fine fragments of the parotid gland were fixed in $2.5 \%$ glutaraldehyde and postfixed in osmium tetraoxide $1.0 \%$, dehydrated in ascending grades of alcohol, cleared in propylene oxide and embedded in epon. Semithin sections were prepared and stained with toluidine blue. Ultrathin sections were prepared and stained with uranyl acetate and lead citrate and examined by Jeol Japan (Jem-1400) transmission electron microscope [15].

\section{RESULTS}

\section{Light microscopic results}

Sections in the parotid gland of control group revealed serous acini with pyramidal cells surrounding a small central lumen with spherical, basal nuclei. The connective tissue stroma showed striated ducts lined with cuboidal epithelium (Fig. 1A). In liquid fed group, there were some areas with degenerated irregularly shaped acini with vacuolated cytoplasm and pyknotic nuclei. The striated ducts showed both pyknotic and ghost shaped nuclei (Fig. 1B-D). Parotid gland of group on liquid diet supplemented with L-car, had normally eosinophilic cytoplasm with few vacuoles in their acinar cells and few nuclei showed pyknotic changes (Fig. 2).

Sections of control group stained with PAS reaction showed serous acini that were strongly stained with PAS with deep magenta colour. The PAS granules were homogeneously distributed into the cytoplasm (Fig. 3A). However, in liquid fed group serous acini were weakly stained with PAS that was localised in the granules within the apical portion of the acini and the vacuoles showed lack of staining (Fig. 3B). 


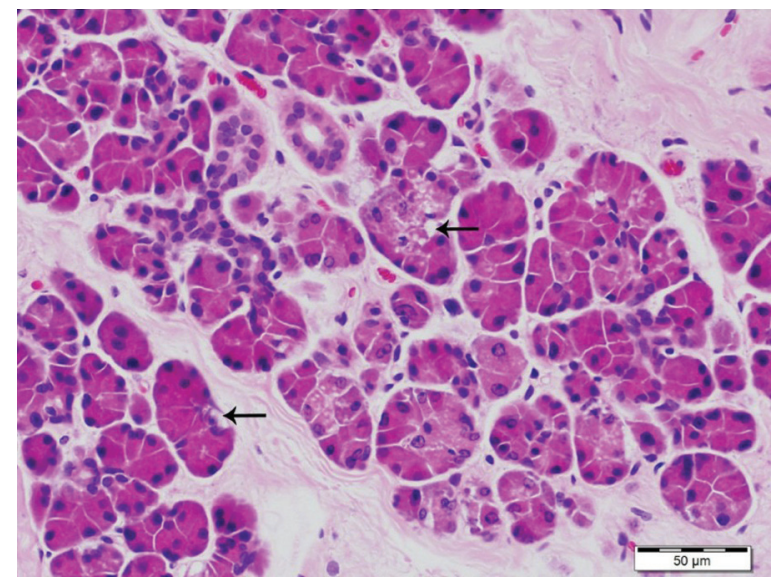

Figure 2. Light photomicrograph of a section in the parotid gland of liquid fed group treated with L-carnitine showing normally eosinophilic cytoplasm with few vacuoles inside their acinar cells (arrows) (H\&E $\times 400)$.

Improvement in the PAS stained acini was seen in group given liquid diet with L-car where it showed moderately stained epithelial cells. The PAS granules were homogeneously distributed into the cytoplasm with few vacuoles within the acinar cells (Fig. 3C).

\section{Immunohistochemical results and their morphometry}

Sections of parotid gland showed weak Caspase 3 immunoexpression in the acinar cells in control group (Fig. 4A). Strong immunoexpression was seen in the acini and more in the ductal epithelium in liquid fed group (Fig. 4B), however, immunoexpression was re- duced markedly in the acinar cells in group on liquid diet supplemented with L-car (Fig. 4C) and similarly the area per cent of Caspase 3 increased markedly in liquid fed group and dropped in L-car supplemented group but still significantly higher than the control group (Table 1, Fig. 5).

\section{Ultrastructural results}

Ultrathin sections of control parotid gland showed acinar cells with abundant secretory granules and the cytoplasmic organelles filling the cell. The nucleus normally shows central homogeneous euchromatin and peripheral condensed heterochromatin. Capillary blood vessels were lying within the collagen stroma in between the acini (Fig. 6A). Parotid gland of liquid fed group showed a degenerated acinar cell with multiple cytoplasmic vacuoles, reduced secretory granules, degenerated dilated mitochondria and dilated cisternae of endoplasmic reticulum (Fig. 6B, C). Acinar cells with degenerated condensed nuclear mass or indented nuclear membrane were seen (Fig. 6C). Some acinar cells had normal heterochromatic nuclei, and others showed degenerated nuclei with finely dispersed chromatin material; some of them showed karyorrhexis where the chromatin material adhered with the nuclear membrane. The cytoplasmic vacuoles showed remains of secretory granules pushed into their margins (Fig. 6D). Also, liquid fed group showed acini with markedly reduced secretory granules in the basal and central parts of acinar cells (Fig. 7A). Other acinar cells revealed absence of the secretory granules and replacement of cyto-
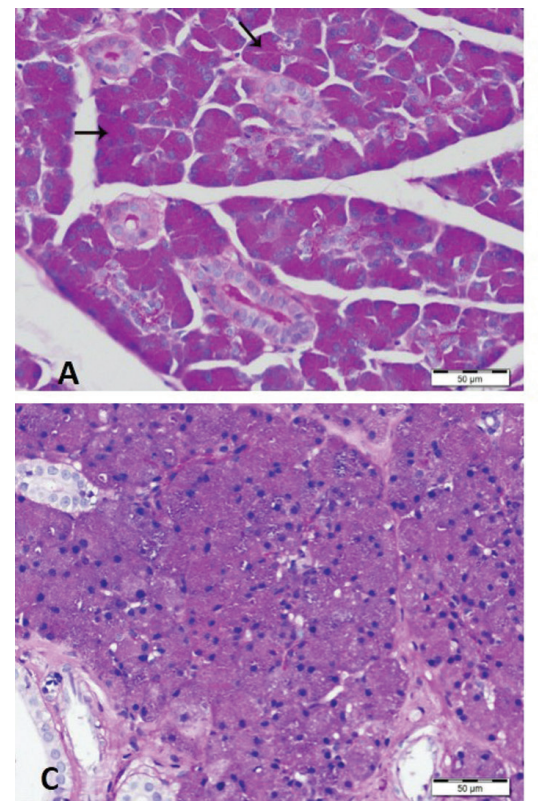

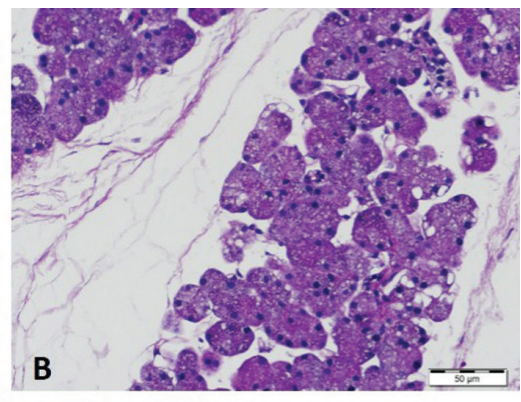

Figure 3. A. Light photomicrographs of sections in the parotid gland showing: A. Serous acini (arrow) of control group strongly stained with periodic acid Schiff (PAS) reaction with deep magenta colour. The PAS stained granules are homogeneously distributed into the cytoplasm; B. Serous acini of liquid fed group that are weakly stained with PAS. The reaction is confined to the granules in the apical portion of the cells and vacuoles inside the acini showed lack of PAS staining; C. Moderately stained serous acini of liquid fed group treated with L-carnitine. The PAS stained granules are homogeneously distributed into the cytoplasm in the parotid gland (PAS $\times 400)$. 

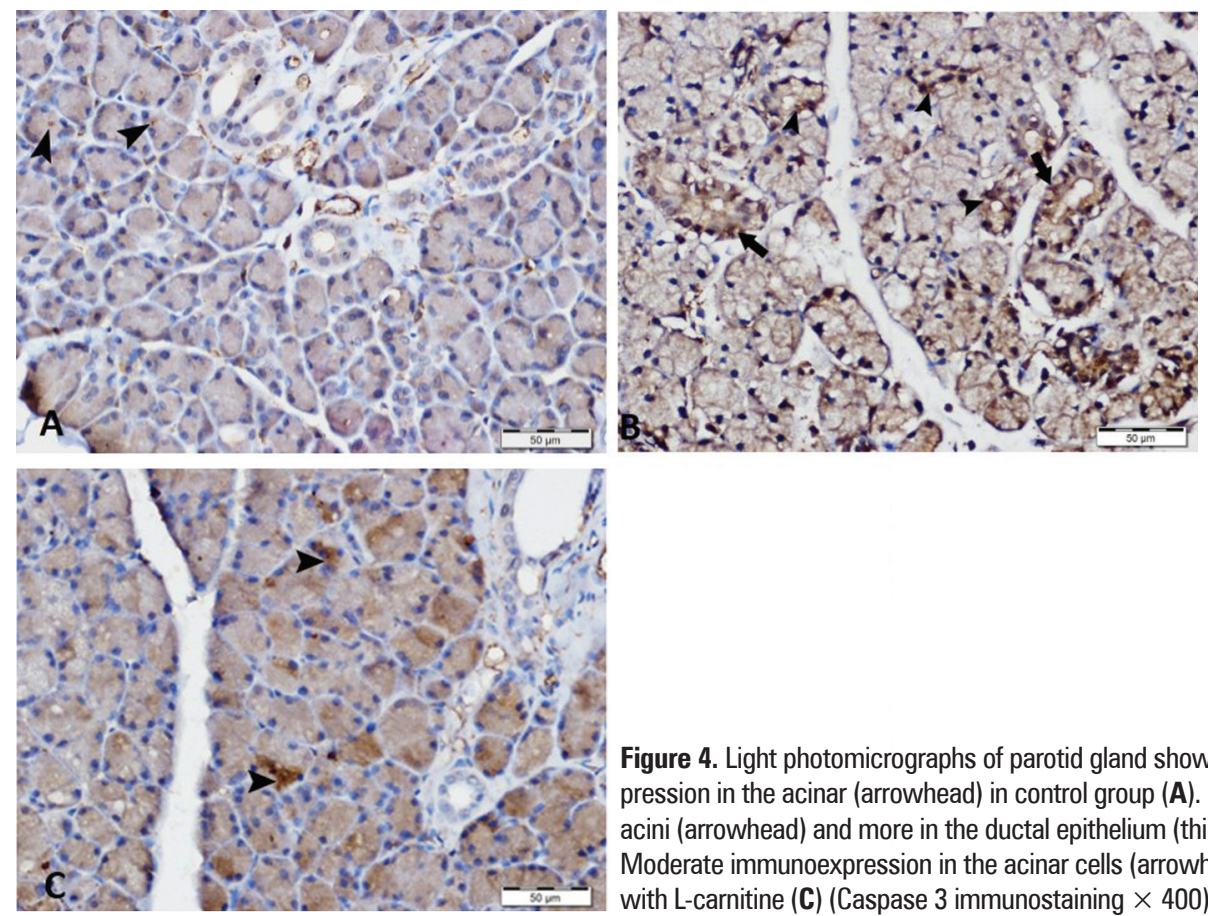

Figure 4. Light photomicrographs of parotid gland showing: weak Caspase 3 immunoexpression in the acinar (arrowhead) in control group (A). Strong immunoexpression in the acini (arrowhead) and more in the ductal epithelium (thick arrow) in liquid fed group (B). Moderate immunoexpression in the acinar cells (arrowhead) in liquid fed group treated with L-carnitine (C) (Caspase 3 immunostaining $\times 400$ ).

Table 1. Mean area per cent \pm standard deviation (SD) of Caspase 3 immunopositivity of the different groups and their statistical significance

\begin{tabular}{lcc}
\hline & \multicolumn{2}{c}{ Caspase 3 } \\
\cline { 2 - 3 } & Mean \pm SD & P \\
\hline Control group & $0.5 \pm 0.16$ & - \\
Liquid diet group & $14.09 \pm 1.59$ & $0.001^{*}$ \\
Liquid diet supplemented & $3.50 \pm 0.33$ & $0.006^{*}$ \\
with L-carnitine group & & \\
\hline
\end{tabular}

*Statistically significant as compared with control $(\mathrm{p}<0.05)$.

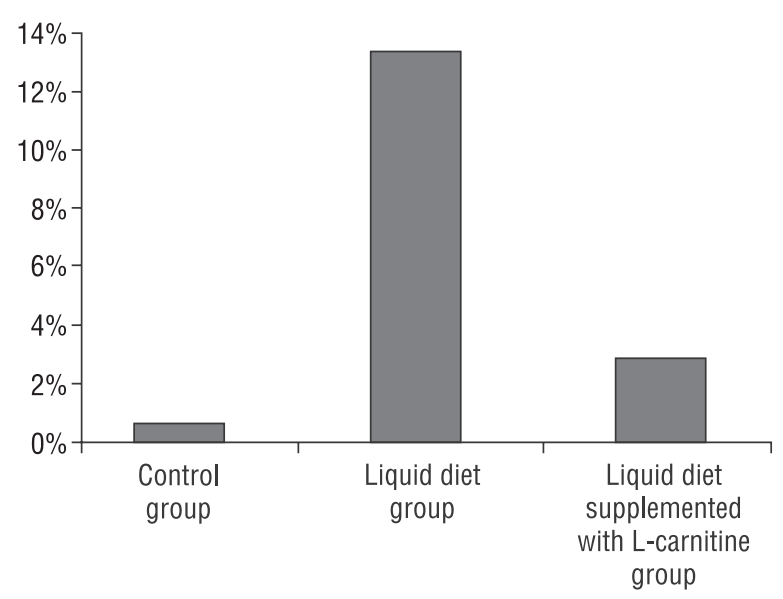

Figure 5. Mean area per cent of Caspase 3 in the different groups. plasmic organelles with homogeneous material. Some cells had only few scattered cytoplasmic organelles with degenerated nuclei showing abnormally dispersed chromatin granules (Fig. 7B). Parotid gland of liquid fed group supplemented with L-car showed acinar cells with normally distributed secretory granules and few cytoplasmic vacuoles. They had normal appearance of the nuclei and their cytoplasmic organelles (Fig. 7C, D).

\section{DISCUSSION}

The influence of consistency of diet on retardation of growth of the jaw bones and masticatory muscles has been established. As the intake of liquid food increases in the human diet, liquid diets retard the growth of human salivary glands and aging changes occurred more rapidly [37]. Understanding the possible mechanisms that alter the functional activity of salivary glands helps to clarify the mechanism of atrophy of salivary glands, as they are playing a significant role in the oral hygiene.

The present findings gave evidence that liquid feeding caused severe cellular degeneration both in the epithelial cells of the acini and their ducts and it varied from cytoplasmic to nuclear changes. The cytoplasmic vacuoles were correlated with the empty spaces in the ultrastructural findings, some of them were partially filled with the secretory granules situated in the 

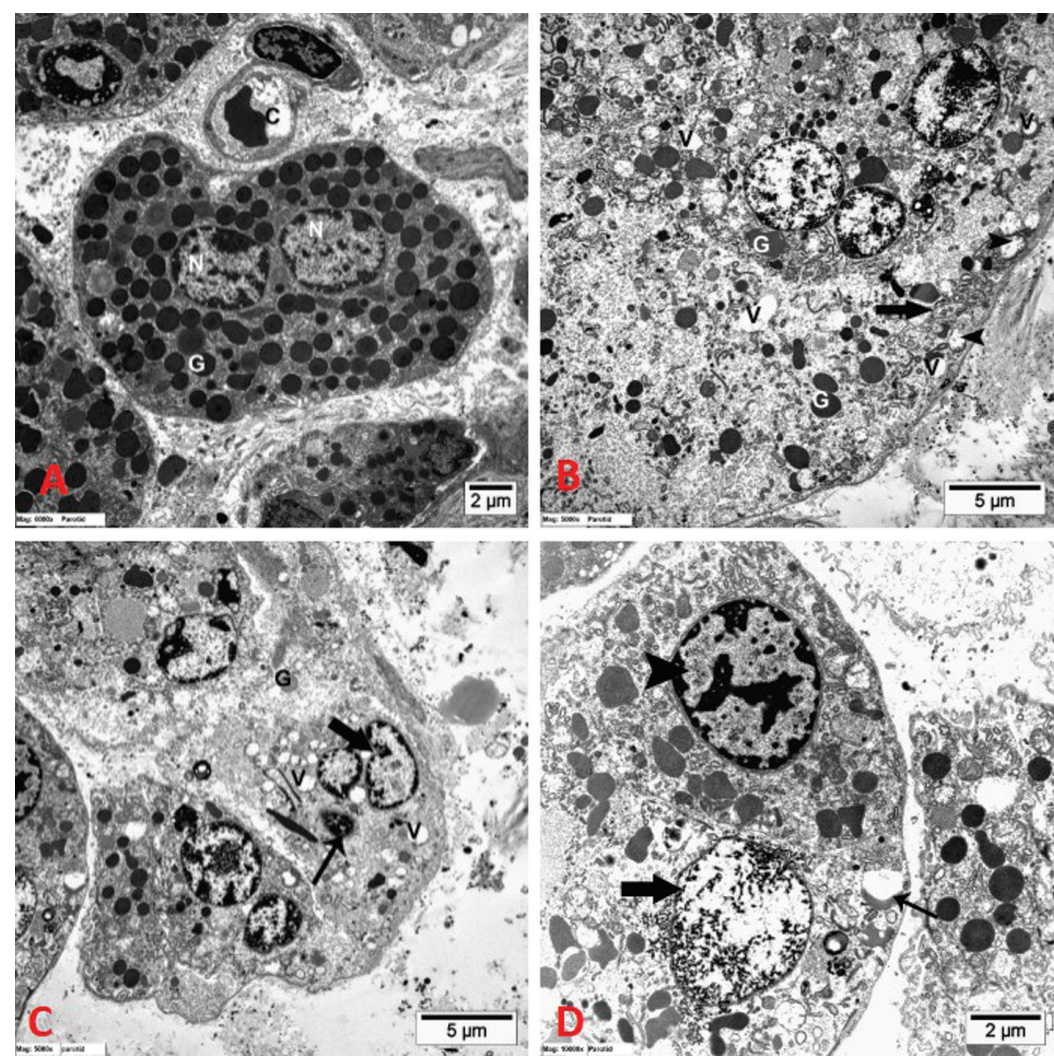

Figure 6. Transmission electron photomicrographs: A. Control parotid gland showing acinar cells with abundant secretory granules $(\mathrm{G})$ and the cytoplasmic organelles are filling the cell. The nuclei (N) show central homogeneous euchromatin and peripheral condensed heterochromatin. Note the capillary blood vessel $(\mathrm{C})$ within the collagen matrix. Parotid gland of liquid fed group; B, C, D. Showing degenerated acinar cells having multiple cytoplasmic vacuoles (V), reduced secretory granules $(G)$, degenerated dilated mitochondria (arrowhead) and dilated cisternae of rough endoplasmic reticulum (thick arrow) (B). Acinar cells with degenerated condensed nuclear mass (arrow), cytoplasmic vacuoles (V), reduced secretory granules (G). Another acinar cell with indented nuclear membrane (thick arrow) are seen (C). Two acinar cells, one shows normal heterochromatic nucleus (arrowhead), and the second with degenerated nucleus with finely dispersed chromatin material; some of them showed karyorrhexis with the chromatin material adhered with the nuclear membrane and others leaked in the cytoplasm (thick arrow). Note the remains of secretory granule pushed into the margin of a secretory granule (arrow) (D). Uranyl acetate and lead citrate: A, B. $\times 6,000$; C. $\times 5,000 ;$ D. $\times 10,000$.
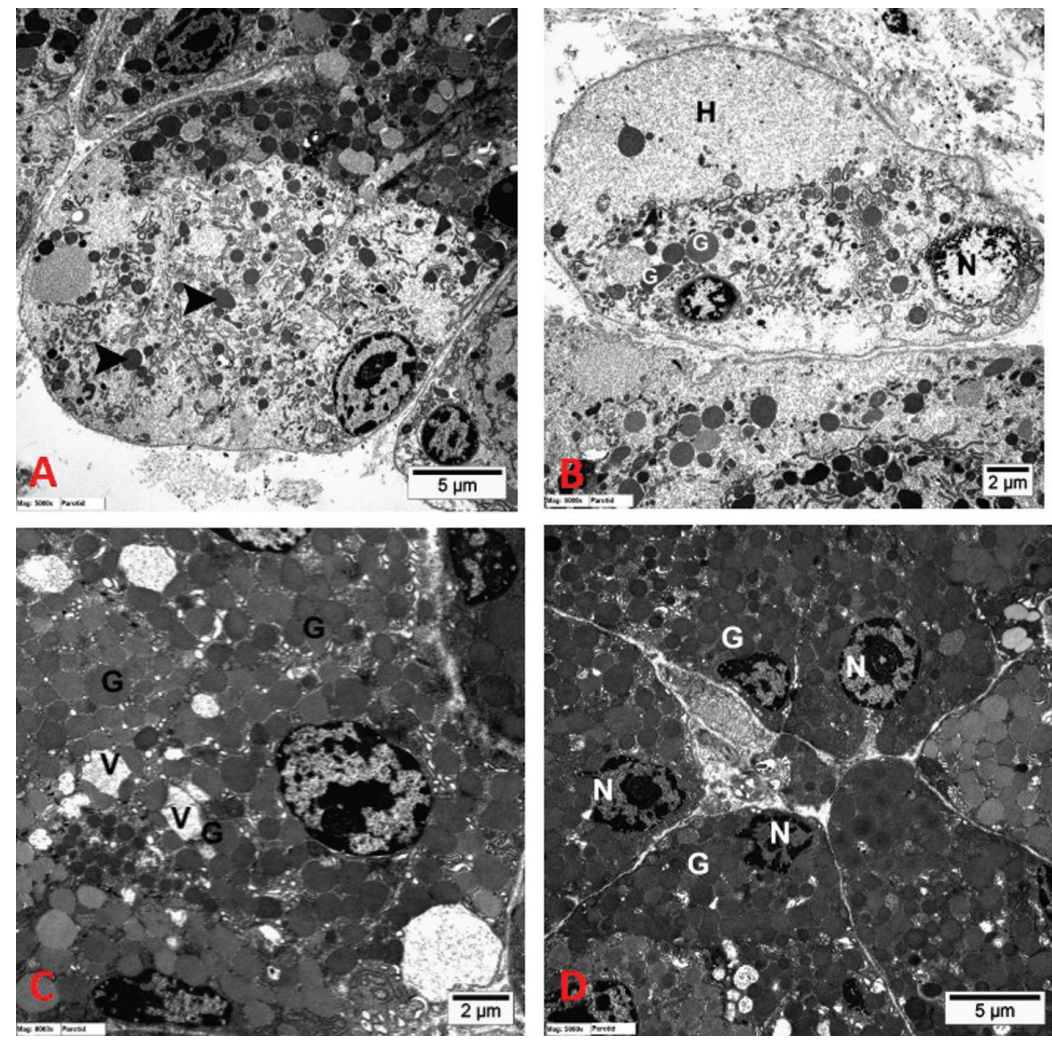

Figure 7. Transmission electron photomicrographs of parotid gland of liquid fed group showing markedly reduced secretory granules (arrowhead) in the basal and central parts of acinar cells (A). Degenerated acinar cells, one of them reveals absence of secretory granules and replacement of cytoplasmic organelles with homogeneous material $(\mathrm{H})$. Other cells reveal markedly reduced secretory granules (G) and scattered cytoplasmic organelles. Degenerated nucleus (N) with abnormally dispersed chromatin granules is also observed (B). C, D. Transmission electron photomicrographs of parotid gland of liquid fed group supplemented with L-carnitine showing acinar cells with normally distributed secretory granules (G) and few cytoplasmic vacuoles (V). Note the normal appearance of the nuclei (N) and cytoplasmic organelles. Uranyl acetate and lead citrate: A, D. $\times 5,000$; B. $\times 6,000$; C. $\times 8,000$ 
periphery of the vacuoles. Striking improvement of the vacuolated cytoplasm and regeneration of cells were seen in L-car supplemented group with abundance of their secretory granules. The present results agree with Leal et al. [26] that the strongest morphological alteration displayed was the presence of cytoplasm vacuoles on the parotid glands of the animals maintained on the liquid diet. Acinar glandular atrophy after liquid feeding is due to acinar cell shrinkage rather than to losses of acinar cell numbers in both parotid and submandibular glands. Previous study claimed that there are varying levels of susceptibility to the loss of masticatory reflexes between parotid and submandibular serous acini with the relative proportion of the vascular bed increased on the expense of atrophied glandular tissue and not actual proliferative tissue to replace an empty space [34].

The areas with lack of PAS staining represented the empty secretory vacuoles due to diminished ability of the glands to form zymogen granules with decreased secretory activity of amylase exerted by the degenerated acini. In agreement with the current results, previous study showed by lectin histochemistry at both light and electron microscopic levels that the secretory granules of parotid gland had sugar residues positively reacting with PAS [36]. Other researchers claimed that the cytoplasmic vacuoles in liquid fed group are watery vacuoles due to lack of membrane exocytosis [28] or reduced water transporting protein aquaporins [42]. On replenishing these granules in L-car group, fewer vacuoles and more positively stained granules were encountered.

It appears that the current degenerative changes evidenced in histological and ultrastructural findings are related to the decrease in chewing in liquid fed group where depending chiefly on suckling movements leading to loss of saliva outflow. This in turn led to lack of parasympathetic stimulation and abolished the trophic stimulation on the acinar cells. Several previous studies had reported that parasympathetic denervation [32] or lack of sufficient masticatory force might lead to a reduced masticatory-parotid reflex and consequent disuse atrophy of the salivary glands $[7,20,21]$.

Extended periods of autonomic denervation, liquid diet feeding (reduced reflex stimulation) or duct ligation cause salivary gland atrophy. The latter two are reversible, demonstrating that glands can regenerate provided that the autonomic innervation remains intact [32]. The submandibular gland wet weight and the differentiation of the acinar cells and convoluted tubule cells of the liquid diet group were retarded. This is in addition to the disappearance of the secre- tory granules and decreased number of acinar cells [22]. Contact of dry food with the oral mucosa rather than the jaw movements involved in mastication that increases parotid gland weight and amylase activity in partial desalivated rats [25].

Apoptosis plays a prominent role in tissue homeostasis [19] and as a mechanism of parotid atrophy in liquid diet regimen was tackled in recent years [38]. The present findings showed that liquid diet induced apoptosis, evidenced by the proapoptotic activated Caspase 3 protein imunoexpression that was significantly upregulated in injured acini. This ensures that it responds to stress by accelerating the programmed cellular demise. The apoptosis was suppressed by supplementation with L-car. In accordance with that, similar findings were recorded in alcohol ingestion, another form of stress facing the salivary gland by diminishing the saliva secretion [35]. Takahashi et al. [38] found more Caspase-3-positive acinar cells and fewer ones with proliferating activity were identified in liquid fed parotid glands and they claimed that was due to decreased parasympathetic nerve stimulation caused by low masticatory stimulation.

The present subcellular changes provides a clue to pathogenic mechanism of degeneration. The mitochondria and endoplasmic reticulum were the main organelles affected, probably from the oxidative damage that propagated to karyorrhexis as a consequence of depriving the cell from energy production. Previous studies reported similar subcellular changes on the pathway of cell apoptosis [2, 33]. Kuntsal et al. [24] detected accumulation of lipid droplets in the acini cells, a finding not seen in the present ultrastructural results, and opposing the notion of lipid degeneration as a potential mechanism. Furthermore, the improvement exerted by L-car due to its antioxidant property supports the oxidative process rather than lipid degeneration. Being a potential scavenger of reactive oxygen species, it prevents the impairment of fatty acid beta-oxidation in mitochondria and protecting tissues from damage [1, 8]. Similar findings using selenium as an antioxidant were reported in a recent work [24] but further studies to quantitatively examine the oxidative enzymes in the parotid tissue on liquid diet are suggested before firm conclusion can be settled.

The present work raises attention that prolonged milk feeding in neonatal period or liquid nutrition in certain clinical situations with shifting from chewing forces to suckling, lead to atrophy of parotid acini with sequelae of diminished salivary flow and negative consequences on the integrity of oral hygiene. 


\section{CONCLUSIONS}

It is concluded that liquid diet caused cellular degenerative damages in both acini and ducts of parotid gland via enhancing apoptotic changes. These changes can be prevented by L-car supplementation probably via its antioxidant properties.

\section{REFERENCES}

1. Arafa HM, Hemeida RA, Hassan MI, Abdel-Wahab MH, Badary OA, Hamada FM (2009) Acetyl-L-carnitine ameliorates caerulein-induced acute pancreatitis in rats. Basic Clin Pharmacol Toxicol, 105: 30-36.

2. Baban B, Liu JY, Abdelsayed R, Mozaffari MS (2013) Reciprocal relation between GADD153 and Del-1 in regulation of salivary gland inflammation in Sjögren syndrome. Exp Mol Pathol, 95: 288-297.

3. Bancroft JD, Cook HC (1994) Immunohistochemistry. In: Manual of histological techniques and diagnostic applications. Churchill Livingstone, Edinburgh, London, Madrid, Melbourne, New York, Tokyo, pp. 236-325.

4. Bancroft JD, Stevens A (1996) Theory and practice of histological techniques. $4^{\text {th }}$ Ed. Churchill Livingstone, London, UK.

5. Binienda ZK, Ali SF (2001) Neuroprotective role of I-carnitine in the 3-nitropropionic acid induced neurotoxicity. Toxicology Lett, 125: 67-73.

6. Boyacioglu M, Turgut H, Akgullu C, Eryilmaz U, Kum C, Onbasili OA (2014) The effect of L-carnitine on oxidative stress responses of experimental contrast-induced nephropathy in rats. J Vet Med Sci, 76: 1-8.

7. Burlage FR, Faber $H$, Kampinga $H H$, Langendijk JA, Vissink A, Coppes RP (2009) Enhanced proliferation of acinar and progenitor cells by prophylactic pilocarpine treatment underlies the observed amelioration of radiation injury to parotid glands. Radiother Oncol, 90: 253-256.

8. Calò LA, Pagnin E, Davis PA, Semplicini A, Nicolai R, Calvani M, Pessina AC (2006) Antioxidant effect of I-carnitine and its short chain esters: relevance for the protection from oxidative stress related cardiovascular damage. Int J Cardiol, 107: 54-60.

9. Cetinkaya A, Kantarceken B, Bulbuloglu E, Kurutas EB, Ciralik H, Atli $Y$ (2013) The effects of L-carnitine and $\mathrm{N}$-acetylcysteine on carbontetrachloride induced acute liver damage in rats. Bratisl Lek Listy, 114: 682-688.

10. Feio M, Sapeta P (2005) Xerostomia in palliative care. Acta Med Port, 18: 459-465.

11. Gao X, Zuo JH, Wang LF, Song SJ, Zhu YH, Chen YY (2012) Expression of programmed cell death 5 and apoptosis during atrophy of the parotid gland cells. Zhonghua Kou Qiang Yi Xue Za Zhi, 47: 694-697.

12. Guerrissi JO (2001) Fractures of mandible: is spontaneous healing possible? Why? When? J Craniofac Surg, 12: 157-166.

13. Gulcin I (2006) Antioxidant and antiradical activities of L-carnitine. Life Sci, 78: 803-811.

14. Hancock S, Cresci G, Martindale R (2002) The clear liquid diet: when is it appropriate? Curr Gastroenterol Rep, 4: 324-331.

15. Hayat MA (2000) Principals and techniques of electron microscopy: biological application. 4th Ed. Cambridge University Press, Edinburgh, UK.

16. Hoppel C (2003) The role of carnitine in normal and altered fatty acid metabolism. Am J Kidney Dis, 41: 4-12.

17. Hughes J, Gobe G (2007) Identification and quantification of apoptosis in the kidney using morphology, biochemical and molecular markers. Nephrology, 12: 452-458.

18. Ito K, Morikawa M, Inenaga K (2001) The effect of food consistency and dehydration on reflex parotid and submandibular salivary secretion in conscious rats. Arch Oral Biol, 46: 353-363.

19. Kapatou E, Skyrlas A, Agelaki MG, Pantos C, Kolettis TM, Malamou-Mitsi V (2010) Amiodarone attenuates apoptosis, but induces phospholipidosis in rat alveolar epithelial cells. J Physiol Pharmacol, 61: 671-677.
20. Kawasaka T, Shimodozono M, Ogata A, Tanaka N, Kawahira K (2010) Salivary secretion and occlusal force in patients with unilateral cerebral stroke. Int J Neurosci, 120: 355-360.

21. Khosravani N, Sandberg M, Ekström J (2006) The otic ganglion in rats and its parotid connection: cholinergic pathways, reflex secretion and a secretory role for the facial nerve. Exp Physiol, 91: 239-247.

22. Kim JH (1990) The effects of solid or liquified diet on the submandibular glands of mice with age. Nihon Kyosei Shika Gakkai Zasshi, 49: 73-86.

23. Kizhakekuttu TJ, Widlansky ME (2010) Natural antioxidants and hypertension: promise and challenges. Cardiovasc Ther, 28: e20-e32.

24. Kuntsal L, Firat D, Sirin Y (2003) Prevention of liquid-diet-induced damages on submandibular glands by selenium supplementation in rats. Tohoku J Exp Med, 201: 191-199.

25. Kurahashi M (2002) The effect of dietary consistency and water content on the parotid glands of submandibular and sublingual duct-ligated rats. Arch Oral Biol, 47: 369-374.

26. Leal SC, Toledo OA, Bezerra AC (2003) Morphological alterations of the parotid gland of rats maintained on a liquid diet._Braz Dent J, 14: 172-176.

27. Maria O, Maria S, Redman R, Maria A, Saad El-Din T, Soussa E, Tran S (2014) Effects of double ligation of Stensen's duct on the rabbit parotid gland. Biotech Histochem, 89: 181-198.

28. Masedunskas A, Sramkova M, Weigert R (2011) Homeostasis of the apical plasma membrane during regulated exocytosis in the salivary glands of live rodents. Bioarchitecture, 1: 225-229.

29. Nahmod KA, Walther T, Cambados N, Fernandez N, Meiss R, Tappenbeck N, Wang $Y$, Raffo D, Simian M, Schwiebs A, Pozner RG, Fuxman Bass Jl, Pozzi AG, Geffner JR, Kordon EC, Schere-Levy C (2012) AT1 receptor blockade delays postlactational mammary gland involution: a novel role for the renin angiotensin system. FASEB J, 26: 1982-1994.

30. Palafox-Carlos H, Ayala-Zavala JF, González-Aguilar GA (2011) The role of dietary fiber in the bioaccessibility and bioavailability of fruit and vegetable antioxidants. J Food Sci, 76: R6-R15.

31. Petrie A, Sabin C (2005) Medical Statistics at a Glance. 2nd Ed. Sugden M, Moore K eds. Blackwell Publishing LTD., USA, pp. 55.

32. Proctor GB, Carpenter GH (2007) Regulation of salivary gland function by autonomic nerves. Auton Neurosci, 133: 3-18.

33. Saggu SK, Chotaliya HP, Blumbergs PC, Casson RJ (2010) Wallerian-like axonal degeneration in the optic nerve after excitotoxic retinal insult: an ultrastructural study. BMC Neurosci, 11: 97.

34. Scott J, Gunn DL (1991) A comparative quantitative histological investigation of atrophic changes in the major salivary glands of liquid-fed rats. Arch Oral Biol, 36: 855-857.

35. Slomiany BL, Piotrowski J, Slomiany A (1997) Chronic alcohol ingestion enhances tumor necrosis factor-alpha expression and salivary gland apoptosis. Alcohol Clin Exp Res, 21: 1530-1533.

36. Takada K, Aiyama S, Ikeda R (2001) Morphological and histochemical changes in the secretory granules of mucouscells in the early postnatal mouse parotid gland. Arch Histol Cytol, 64: 259-266.

37. Takahashi S, Uekita H, Kato T, Yuge F, Ushijima N, Inoue K, Domon T (2014) Immunohistochemical and ultrastructural investigation of acinar cells in submandibular and sublingual glands of rats fed a liquid diet. Tissue Cell, 36: 136-143.

38. Takahashi S, Uekita H, Kato T, Yuge F, Ushijima N, Inoue K, Domon T (2012) Involvement of apoptosis and proliferation of acinar cells in atrophy of rat parotid glands induced by liquid diet. J Mol Histol, 43: 761-766.

39. Valko M, Izakovic M, Mazur M, Rhodes CJ, Telser J (2004) Role of oxygen radicals in DNA damage and cancer incidence. Mol Cell Biochem, 266: 37-56.

40. Wu X, Zhang Q, Wang X, Zhu J, Xu K, Okada H, Wang R, Woo M (2012) Survivin is required for beta-cell mass expansion in the pancreatic duct-ligated mouse model. PLoS One, 7: e41976.

41. Yahiro J, Inai T, Tsutsui A, Sato A, Nagato T, Taniguchi K, Tsuruga E, Sawa Y (2011) Immunohistochemical and immunocytochemical localization of amylase in rat parotid glands and von Ebner's glands by ion etching-immunoscanning electron microscopy. Acta Histochem Cytochem, 44: 201-212.

42. Yanagi Y, Yasuda M, Hashida K, Kadokura Y, Yamamoto T, Suzaki H (2008) Mechanism of salivary secretion enhancement by Byakkokaninjinto. Biol Pharm Bull, 31: 431-435. 